\title{
ACCURACY OF LAND-USE INTERPRETATION FROM INFRARED IMAGERY IN THE 4.5 TO 5.5 MICRON BAND
}

\author{
CHARLES E. OLSON, JR. \\ Willow Run Laboratories \\ University of Michigan, Ann Arbor
}

\begin{abstract}
Infrared imagery in the 4.5 to 5.5 micron wavelength band was obtained in July, 1965. Interpretation and subsequent field checking indicated that differences in agricultural land use can produce tone differences in infrared imagery and that these differences tend to be more pronounced in day than in night imagery. Differences in soil fertility and cultivation practices were observed that created significant differences in tone of a single crop. The value of first-hand field information in the area being interpreted was clearly demonstrated.

Interpretation accuracies of ninety percent for separation of cultivated and noncultivated lands, ninety-five percent for recognition of alfalfa, seventy percent for corn, sixtyfive percent for soybeans, and eighty-five percent for separation of wooded and nonwooded areas of noncultivated lands were achieved. Interpretation of tree species and separation of pasture and brush lands were not achieved with an accuracy of over fifty percent.
\end{abstract}

$I^{\mathrm{N}}$ NFRARED technology has advanced so rapidly that airborne sensing systems can now generate imagery of such high quality that it resembles conventional aerial photography. The manner in which the imagery is produced has been described many times and will not be repeated here. ${ }^{1}$ However, it is pertinent to comment at this point that most tests of infrared systems seem to yield imagery of higher overall quality at night than in the daytime. Because of this, daytime imagery is relatively rare and most of what does exist has been generated under military auspices that prevents its open dissemination.

In July, 1965, the University of Michigan acquired unclassified imagery of areas in Michigan and Minnesota from the United States Forest Service. This imagery was generated during equipment checks preparatory

Accepted for publication April 26, 1966.

\footnotetext{
${ }^{1}$ G. H. Suits, "The Nature of Infrared Radiation and Ways to Photograph It," Photogrammetric Engineering, Vol. 26 (1960), pp. 763-72; J. O. Morgan, "Infrared Technology," Proceedings of the First Symposium on Remote Sensing of Environment, held at Ann Arbor, Michigan, Report No. 4864-1-X, Institute of Science and Technology, The University of Michigan, Ann Arbor, Mich., February, 1962; D. E. Harris, and C. L. Woodbridge, "Terrain Mapping by Use of Infrared Radiation," Photogrammetric Engineering, Vol. 30 (1964), pp. 134-39.
}

to other research and, although of variable quality, includes both day and night data. An opportunity to interpret and field check selected imagery arose in August.

Imagery for an area close to Ann Arbor, Michigan, was interpreted and field checked early in August. Panchromatic/minus-blue aerial photography of the selected area (Fig. 1) reveals a mixed land-use pattern with active agriculture, abandoned fields, patches of woods, new subdivisions, and super-highways intermingled. Infrared imagery for this area was obtained late on the night of July 20 and is shown in Figure 2. The night was clear, the aircraft was approximately 10,000 feet above the ground, and an indium antimonide detector filtered to the 4.5 to 5.5 micron band was used.

The extremely light tone of the river and several small ponds shown in Figure 2 is characteristic of infrared imagery obtained at night, and results from more rapid cooling of land than water surfaces after sunset. Wooded areas also show in lighter tones than the surrounding brush and crop lands, and this is believed to be the result of higher air temperatures in the woods than the surrounding fields. Although fields of alfalfa, corn, and wheat were all present in the area, crop types cannot be distinguished from the imagery be- 


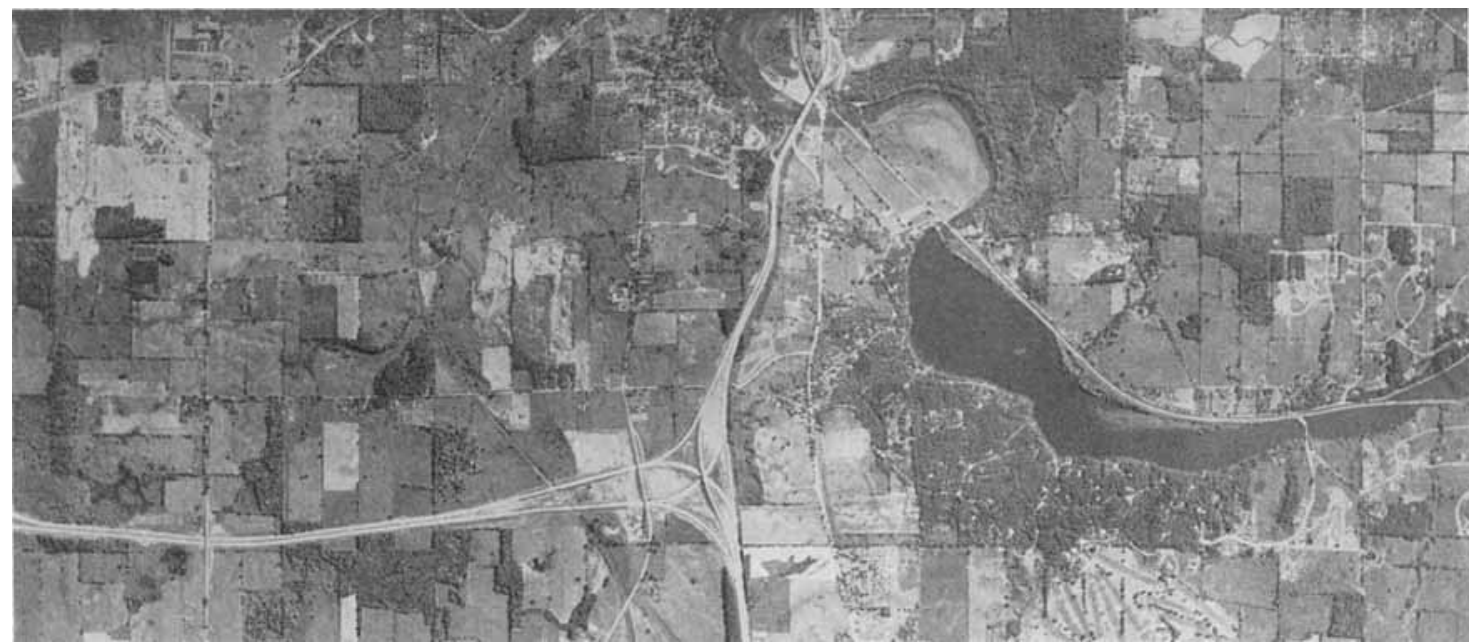

FIG. 1. Panchromatic/Minus-Blue Photograph of an Area Near Ann Arbor, Michigan, Taken on September 14, 1963. (USDA Photo.)

cause all crops appear in the same middlegray tones. The darkest toned areas are low swampy spots.

Brief examination of the daytime imagery acquired from the Forest Service revealed considerable tone contrast from one field to the next and led to the belief that crops and land use might be more readily interpreted from day than night imagery. We know that transpiration of green plants occurs almost exclusively in the daytime and that different crops may develop quite different levels of moisture stress under a given set of conditions.
During the night, cessation of transpiration permits water uptake by plants to reduce water deficits in the foliage. High moisture stress is usually accompanied by increased foliage temperatures and Weber's work with red pine indicates that emissivity of plant foliage increases at high levels of moisture stress. ${ }^{2}$ Since temperature and emissivity both

${ }^{2}$ F. P. Weber, Exploration of Changes in Reflected and Emitted Radiation Properties for Early Remote Detection of Tree Vigor Decline, Unpublished M. F. thesis presented to the University of Michigan School of Natural Resources, December, 1965.

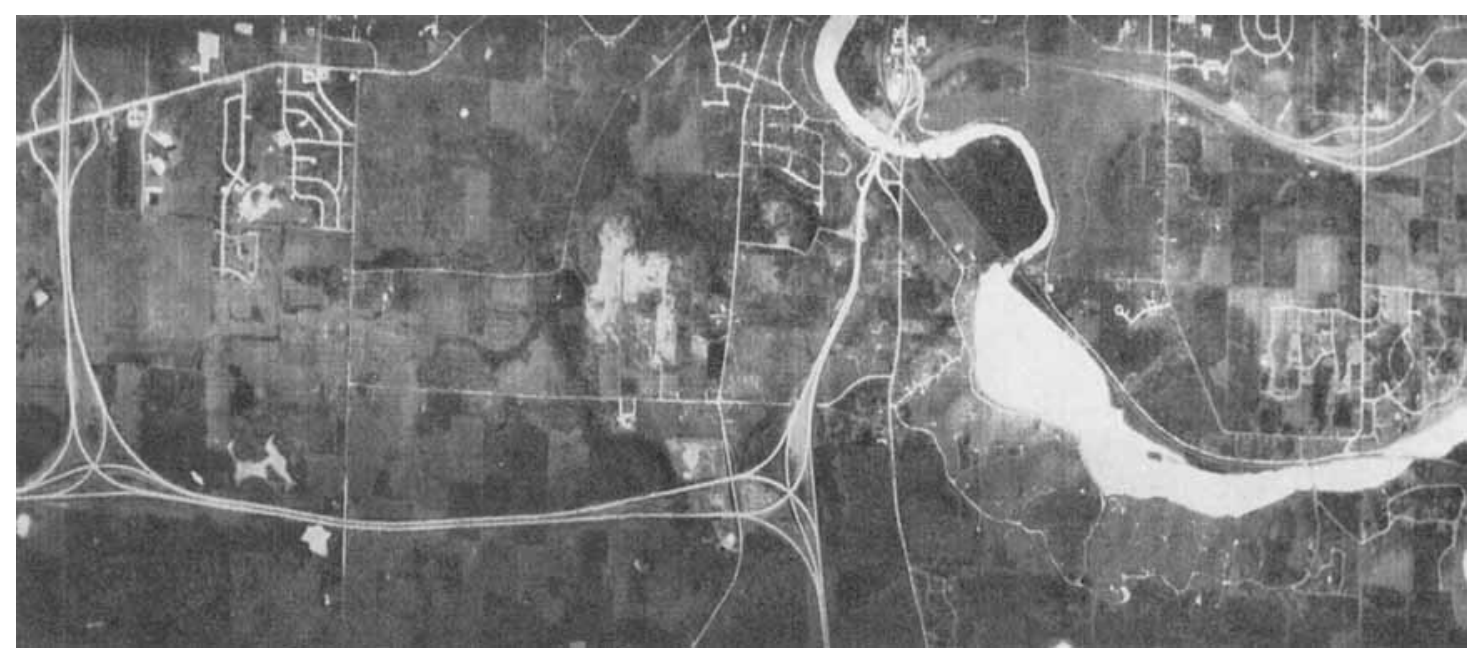

Fic. 2. Infrared Imagery in the 4.5 to 5.5 Micron Band of the Area Near Ann Arbor, Michigan, Shown in Figure 1. This imagery was obtained late on the night of July 20, 1965, from an altitude of approximately 10,000 feet. (Courtesy of the U.S. Forest Service.) 
tend to increase as moisture stress increases, plants under high moisture stress should emit more energy and should appear in infrared imagery in lighter tones than plants under lesser amounts of moisture stress. These arguments were considered sufficient to justify a more detailed analysis of the daytime imagery.

Two areas were selected for study. One in Wright County, Minnesota, approximately thirty-five miles west of Minneapolis; and the second in Leelanau County, Michigan, along the Lake Michigan shore approximately 250 miles northwest of Detroit (Fig. 3). Imagery of both areas came from the Forest Service scanner equipped with an indium antimonide detector filtered to the 4.5 to 5.5 micron band. The Minnesota imagery was generated at approximately 1130 hours, local standard time, on July 14. Aircraft altitude was approximately 10,000 feet above ground and the sky was clear except for scattered cumulus clouds well below the aircraft. The Michigan imagery was generated at approximately 1530 hours, local standard time, on July 23, when the aircraft was flying at approximately 6,000 feet above ground and just beneath a uniform cloud layer that significantly reduced insolation.

\section{PROCEDURES}

Selected imagery from both states was interpreted in early August. Areas occupied by homes and other buildings were omitted and all remaining areas classed as either cultivated or noncultivated. For this purpose, alfalfa, corn, soybeans, oats, wheat, and sudan grass were all considered cultivated crops although some of these are not actually cultivated in the agricultural sense. Within the cultivated grouping further classification to crop type was attempted. Similar subdivision of noncultivated lands seemed impossible but an attempt was made to classify them as wooded or nonwooded, with probable species being recorded for wooded areas.

Late in August both the Minnesota and Michigan localities were visited on the ground. In each state, the first day's field activities were restricted to an area of approximately four square miles. Based upon this first-hand information, a second four square mile block in that locale was reinterpreted and these new interpretations field checked for accuracy. During each reinterpretation, subdivision of noncultivated lands into pasture, brush, and wooded lands was attempted, but otherwise the classification scheme was the same as for the first interpretation. Both the first and second interpretations, as well as all field checking, were performed by the author.

After all field checking had been completed, the data were analyzed to determine interpretation accuracy in:

1) separating cultivated from noncultivated lands,

2) interpreting crop type for cultivated lands,

3) separating wooded from nonwooded lands within the noncultivated grouping,

4) interpreting tree species for wooded lands,

5) separating brush from pasture lands for nonwooded areas (reinterpretation only).

\section{RESULTS}

Data analysis was based on all fields in each block for which actual land use at the time of overflight had been determined in the field. Inability to locate some land owners (or tenants) in the time available, made it impossible to determine land use on July 14 for some fields that were freshly plowed at the time of the field check. These fields, and those for which land use could not be determined without illegal trespass, were not considered during this analysis.

Accuracy of crop type interpretations was so low prior to field checking of the first area in each locale that the data for all cultivated crops have been combined for the first interpretations. Results of the original and second interpretations for the Minnesota and Michigan locales are shown in Tables 1 and 2, respectively. Differences between the accuracies achieved in the two localities were small and the data have been combined in Table 3 .

Interpretation accuracy, as used in the tables, is the percentage of total possible correct interpretations that were actually inter- 
TABLE 1.-ACGURACY OF LAND-USE INTERPRFTATIONS in Wright County, Minnesota, hrom DaytTMe, INFRARED IMAGERY IN THE 4.5-5.5 $\mu$ WAVELENGTH REGION

\begin{tabular}{|c|c|c|c|}
\hline Level of interpretation & $\begin{array}{l}\text { Number } \\
\text { of } \\
\text { chances }\end{array}$ & $\begin{array}{c}\text { Num- } \\
\text { ber } \\
\text { right }\end{array}$ & $\begin{array}{c}\text { Accu- } \\
\text { racy }\end{array}$ \\
\hline \multicolumn{4}{|l|}{ Prior to field check* } \\
\hline $\begin{array}{l}\text { Cultivated vs. } \\
\text { non-cultivated }\end{array}$ & 204 & 142 & $70 \%$ \\
\hline Crop type & 153 & 38 & $25 \%$ \\
\hline Wooded vs. non-wooded & 51 & 31 & $61 \%$ \\
\hline Tree species & 16 & 1 & $6 \%$ \\
\hline \multicolumn{4}{|l|}{ After initial field check* } \\
\hline $\begin{array}{l}\text { Cultivated vs. } \\
\text { non-cultivated }\end{array}$ & 127 & 118 & $93 \%$ \\
\hline Alfalfa & 30 & 28 & $93 \%$ \\
\hline Corn & 43 & 31 & $72 \%$ \\
\hline Soybeans & 23 & 15 & $65 \%$ \\
\hline Wooded vs. non-wooded & 22 & 20 & $91 \%$ \\
\hline Brush vs. pasture & 10 & 2 & $20 \%$ \\
\hline Tree species & 6 & 3 & $50 \%$ \\
\hline
\end{tabular}

preted correctly. For the first area in the Minnesota locale, 204 fields were classified and subsequently field checked. Of these, 142 were correctly classed as cultivated or noncultivated, giving an interpretation accuracy of seventy percent. For the second area in the Minnesota locale, thirty of the fields classified and subsequently field checked were actually fields of alfalfa. Of these, twenty-eight were correctly interpreted as alfalfa, for an accuracy of ninety-three percent. One of the two alfalfa fields that were incorrectly interpreted was classed as corn and the other as wooded, but these two errors were not considered when computing the interpretation accuracies shown in the tables for corn and wooded areas.

Somewhat different accuracy levels can be calculated by using interpreted land use as the base. When this is done with the combined data for the second area interpreted in each locale, we find that of fifty-six fields interpreted as alfalfa, forty-five were actually in this crop; an accuracy of eighty percent. Similar comparisons for corn and soybeans yield accuracies of seventy-three and fiftyone percent, respectively; and of 148 fields interpreted as cultivated, seventy percent were correctly labelled as to crop type.

If the total classification scheme had been limited to five classes (alfalfa, corn, soybeans,
TABLE 2.-ACCURACY OF LAND-USE INTERPRETATIONS in Leelanau County, Michigan, From Daytma INFRARED IMAGERY IN THE 4.5-5.5 $\mu$ WAVELENGTH REGION

\begin{tabular}{|c|c|c|c|}
\hline Level of interpretation & $\begin{array}{l}\text { Number } \\
\text { of } \\
\text { chances }\end{array}$ & $\begin{array}{c}\text { Num- } \\
\text { ber } \\
\text { right }\end{array}$ & $\begin{array}{l}\text { Accu- } \\
\text { racy }\end{array}$ \\
\hline \multicolumn{4}{|l|}{ Prior to field check* } \\
\hline $\begin{array}{l}\text { Cultivated vs. } \\
\text { non-cultivated }\end{array}$ & 130 & 92 & $71 \%$ \\
\hline Crop type & 72 & 18 & $25 \%$ \\
\hline Wooded vs. non-wooded & 58 & 46 & $79 \%$ \\
\hline Tree species & 24 & 3 & $12 \%$ \\
\hline \multicolumn{4}{|l|}{ After initial field check* } \\
\hline $\begin{array}{l}\text { Cultivated vs. } \\
\text { non-cultivated }\end{array}$ & 94 & 75 & $86 \%$ \\
\hline Alfalfa & 18 & 17 & $94 \%$ \\
\hline Corn & 10 & 6 & $60 \%$ \\
\hline Soybeans & - & - & - \\
\hline Wooded vs. non-wooded & 63 & 53 & $84 \%$ \\
\hline Brush vs. pasture & 25 & 9 & $36 \%$ \\
\hline Tree species & 19 & 8 & $42 \%$ \\
\hline
\end{tabular}

other cultivated crops, and noncultivated) 171 out of 221 possible fields would have been correctly identified during the interpretation of the second area in each locale; an interpretation accuracy of seventy-seven percent.

\section{DISCUSSION}

Three factors were primarily responsible for the seventy percent success rate in separating cultivated and noncultivated areas during the initial interpretations. One of these was the regular pattern superimposed on cultivated areas by the legal land survey lines in both areas. This permitted most of the irregular areas that were not strip-cropped to be correctly classed as noncultivated. The second factor was the relative scarcity of noncultivated land in the Minnesota locale; and the third factor was the author's prior familiarity with land use in Leelanau County, Michigan, where farm fields are relatively small when compared with the larger wooded areas. In Leelanau County, large areas of cultivated crops could usually be distinguished from wooded areas, for field lines could be discerned in the former.

The initial interpretations were distinctly hampered by lack of ground information and even minimal ground data would have resulted in a significant increase in accuracy for 


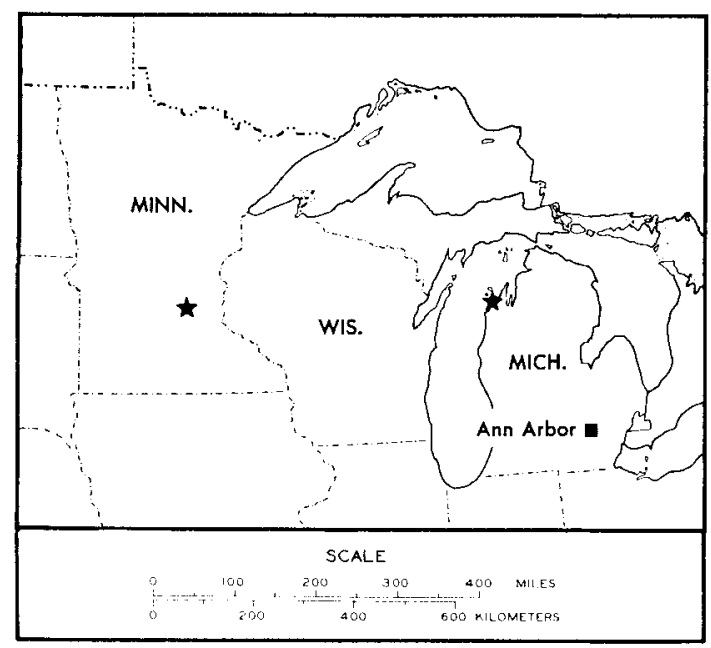

FIG. 3. Location of the Test Areas (Stars) in Wright County, Minnesota, and Leelanau County, Michigan.

crop type interpretations. As an example, forty of the eighty-two alfalfa fields encountered in field checking the initial interpretations had been labelled soybeans, indicating that definite characteristics were recognizable but attributed to the wrong crop. If this gross error had been avoided, accuracy of interpretation for alfalfa would have risen from thirteen to nearly fifty percent for the initial interpretations. This, plus the remarkable similarity in results for the Minnesota and Michigan localities, seems to indicate that most of the twenty-five percent success rate for crop type interpretations prior to any field checking can be attributed to chance.

After preliminary field checking of the first area in Minnesota, accuracy of crop type interpretation increased for all crops, but most strikingly so for alfalfa which was uniformly dark-toned in the imagery (Fig. 4). Corn and soybeans appeared in medium gray tones and looked so similar that they were often hard to separate. Soybeans were the common cover crop on fields retired under the Soil Bank program and these fields were seldom cultivated after planting. Thus, many of the soybean fields were atypical. The mottled appearance of these fields did provide a primary guide to separation of corn and soybeans, however.

Separation of wooded and nonwooded lands was based primarily on tone, once the area

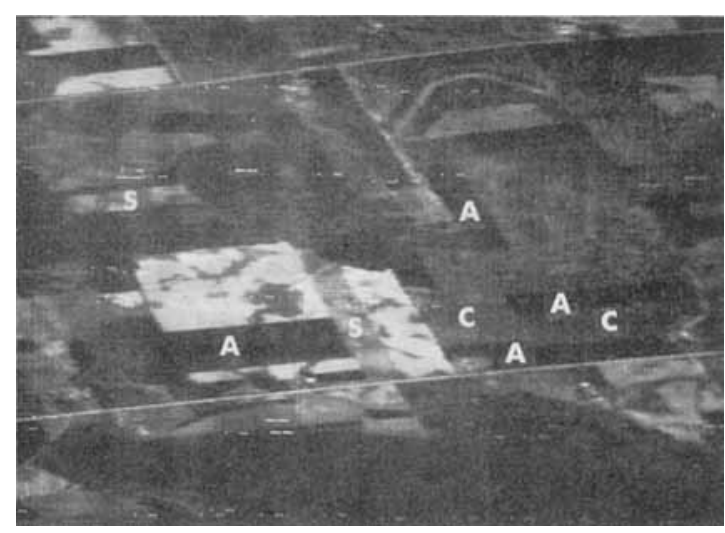

FIG. 4. Infrared Imagery in the 4.5 to 5.5 Micron Band of an Area in Wright County, Minnesota, Obtained from an Altitude of 10,000 Feet Near Noon on July 14, 1965. Annotation A is an alfalfa field, $\mathrm{C}$ is corn, and $\mathrm{S}$ is soybeans. (Courtesy of U.S. Forest Service.)

had been classed as noncultivated. Since wooded areas tend to be cooler than nonwooded areas during mid-day and early afternoon, wooded areas tend to appear in distinctly darker tones than surrounding fields on infrared imagery obtained in the daytime.

Original interpretations of tree species were only guesses, but the first field check revealed that only five or six species were common in a single locality. As a result, subsequent interpretations of tree species were based entirely on ecological considerations. In Minnesota, most wooded areas were found where the land was too rough or wet to cultivate, and these site considerations further reduced the number of species that had to be considered. The Michigan study area is located on extensive deposits of glacial till, interspersed with swamps in some of the low places (Fig. $5)$. Under these conditions species interpretation becomes primarily a problem in site interpretation.

Separation of brush and pasture lands remained so poor that it is hard to attribute the limited success rate to anything but chance. The fact that many pastures contained scattered trees undoubtedly contributed to this lack of success.

Increased interpretation accuracy achieved after field checking the first area in each locale was expected, for similar results are almost always obtained when working with 


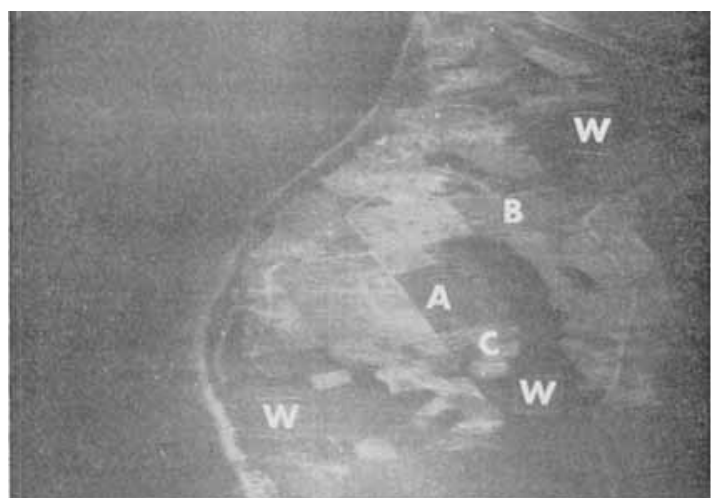

FIG. 5. Infrared Imagery in the 4.5 to 5.5 Micron Band of an Area in Leelanau County, Michigan, Obtained from an Altitude of 6,000 Feet at 1530 on July 23, 1965. Annotation A is an alfalfa field, B is abandoned, $\mathrm{C}$ is corn, and $\mathrm{W}$ is a wooded area. (Courtesy of U.S. Forest Service.)

standard aerial photographs. However, both the size of the increase in accuracy, and the final level of accuracy, in interpretation of crop type were pleasant surprises. It is doubtful that these levels of success could be maintained over a large area containing a greater diversity of crops and land forms, yet the results strongly indicate that current field knowledge in the area being interpreted greatly increases the accuracy of land-use interpretations.

The fact that soil differences can significantly influence the tonal appearance of a single crop type was demonstrated during the field check of the first area in Minnesota. Two fields of corn growing side by side on sites that appeared similar in all respects were recorded with distinctly different tones in the imagery (Fig. 6). Further investigation revealed that both fields contained the same variety of corn, were planted on the same day, and had received the same fertilizer treatment. However, the darker-toned field had been in alfalfa for the three preceding years and the other field in corn for the last five years. Increased nitrogen levels and high moisture in the spring had produced more extensive root systems and luxuriant vegetative growth in the former alfalfa field that were not matched in the field under continuous corn.

It is probable that any real value which this small study may have lies in its proof that differences in land use do produce rec-

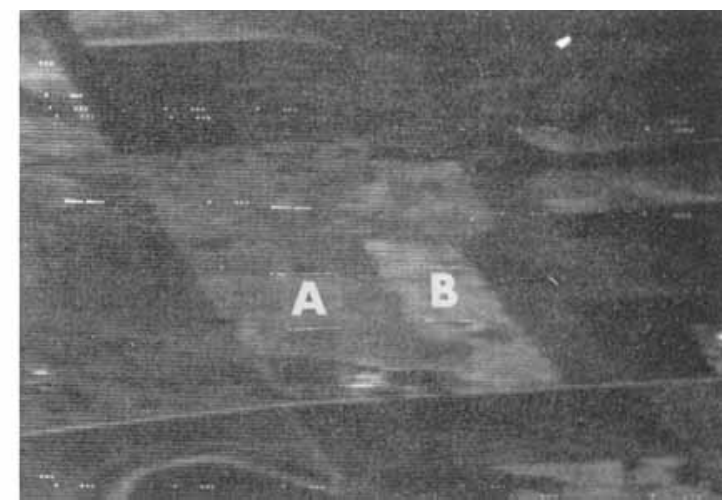

Frg. 6. Infrared Imagery in the 4.5 to 5.5 Micron Band of Two Corn Fields in Wright County, Minnesota. Field A had been in alfalfa for the three preceding years and Field $B$ in continuous corn. (Courtesy of U.S. Forest Service.)

ognizable differences in the tone of infrared imagery, rather than in any proof it may offer that land use can be interpreted directly from imagery in the 4.5 to 5.5 micron band. Similar, or better results in land-use interpretation can often be achieved at lower cost using panchromatic aerial photography. However, it is unlikely that errors in land-use interpretation associated with aerial photographs would be the same as those associated with infrared imagery. Thus, comparative inter-

Table 3.-ACCURACY OF LAND-USE INTERPRETATIONS FROM DAYTIME, INFRARED IMAGERY IN THE 4.5-5.5 $\mu$ Wavelength Region. (Summary for Wright County, Minnesota, and Leelanau County, Michigan)

\begin{tabular}{lrrr}
\hline \multicolumn{1}{c}{$\begin{array}{c}\text { Level of } \\
\text { interpretation }\end{array}$} & $\begin{array}{c}\text { Number of } \\
\text { chances }\end{array}$ & $\begin{array}{c}\text { Number } \\
\text { right }\end{array}$ & $\begin{array}{c}\text { Accu- } \\
\text { racy }\end{array}$ \\
\hline $\begin{array}{l}\text { Prior to field check* } \\
\text { Cultivated vs. }\end{array}$ & & & \\
$\quad$ non-cultivated & 334 & 234 & $70 \%$ \\
Crop type & 225 & 56 & $25 \%$ \\
Wooded vs. non-wooded & 109 & 77 & $71 \%$ \\
Tree species & 40 & 4 & $10 \%$ \\
After initial field check* & & & \\
Cultivated vs. & & & \\
$\quad$ non-cultivated & 221 & 193 & $90 \%$ \\
Alfalfa & 48 & 45 & $94 \%$ \\
Corn & 53 & 37 & $70 \%$ \\
Soybeans & 23 & 15 & $65 \%$ \\
Wooded vs. non-wooded & 85 & 73 & $86 \%$ \\
Brush vs. pasture & 35 & 11 & $31 \%$ \\
Tree species & 25 & 11 & $44 \%$ \\
\hline
\end{tabular}

* The first area interpreted was field-checked by the interpreter prior to interpreting the second area. Source: Calculated by author. 
pretation of both aerial photographs and infrared imagery-called multispectral interpretation by Colwell (1965)-should produce better results than interpretation of either type of imagery alone.

\section{CONCLUSTONS}

Three conclusions seem justifiable from the data available at this time, even though accuracies achieved during this study may be impossible to duplicate in other geographic areas.

1) Differences in agricultural land use can produce tone differences in infrared imagery in the 4.5 to 5.5 micron band. For the areas and conditions included in this study, these differences were more pronounced, and hence easier to interpret, in imagery obtained during mid-day and early afternoon than in imagery obtained at night.

2) Differences in soil fertility and cultivation practices can cause any one crop to appear in widely varying tones in infrared imagery in the 4.5 to 5.5 micron band.

3) Current field knowledge of the area being interpreted greatly increases the accuracy of land-use interpretations from infrared imagery. The importance of frequent field checks by the interpreter, when conditions permit, is hard to overemphasize. 